\title{
Kala azar in Nepal: Estimating the effects of socioeconomic factors on disease incidence
}

\author{
Adhikari SR ${ }^{1}$, Supakankunti S', Khan MM² \\ ${ }^{1}$ Faculty of Economics, Chulalongkorn University, Thailand, ${ }^{2}$ Tulane University, New Orleans USA
}

\begin{abstract}
Background: The incidence of Kala Azar (KA), a neglected tropical infectious disease, describes the pattern of disease, but is not principally concerned with explaining its causes. The transmission of the infectious diseases is determined by the complex interactions between environmental and socioeconomic factors. Environmental factors are predicted to have a significant impact on disease transmission; moreover, socioeconomic factors modify the magnitude and direction of these impacts. A number of studies have examined possible determinants of KA in endemic countries of the world; however, most of them appear to have used either qualitative approaches or subjective speculations. None of the studies indicates in quantitative terms the potential effects of poverty-alleviation programs on the incidence of KA.

Materials and methods: Data related to charecteristics of community were collected from primary as well as secondary sources. Underlying socioeconomic determints on KA incidence were estimated by exploiting a linear multiple regression.

Results: The multivariate analysis has confirmed that burden of KA is disproportionately borne by vulnerable and marginalized groups. KA is most entrenched in the poorest communities. Elimination of KA is directly related to poverty alleviation because if the poverty incidence reduces by10 percent, it will lead to reduction of KA incidence by 16 percent. The strategy for disease control or elimination should shift from traditional disease-centered approaches to a holistic approach that can break the links between poverty and KA.

Conclusions: To achieve the target of elimination of KA in Nepal by 2015, the poverty incidence should be reduced from existing poverty 27 percent to at least 16 percent in KA endemic areas. The association between poverty and KA reflects causality running in both directions: poverty multiplies KA incidence and KA pushes poor into marginal poor or further poverty.
\end{abstract}

Key words: Kala azar, Socioeconomic factors, Leishmaniasis

\begin{abstract}
$\mathrm{A}$ ccording to the World Health Organization (WHO), Leishmaniasis remains endemic in 88 countries of the world with an annual incidence of about two million cases. Although the global incidence of visceral Leishmaniasis or Kala Azar (KA) is about half a million per year, $90 \%$ of these cases are found in Bangladesh, Brazil, India, Nepal and Sudan. The re-emergence of KA requires systematic analysis of the potential determinants ${ }^{1}$. The environmental and geographical factors are important determinants of KA incidence but health policy changes are not that effective in altering these factors. Policy relevant socioeconomic determinants are more important in designing effective health interventions.
\end{abstract}

We know that a number of important determinants of the disease are systematically associated with social disadvantage and marginalization ${ }^{2}$ but little is known about the causal pathway from the community level characteristics to the disease incidence. Social factors like government expenditure, population density, income distribution, poverty, infrastructural development and other community-level factors modify the magnitude and direction of KA transmission probability, given the environmental conditions and geographical situation. For the success of disease control activities, it is important to design interventions by taking into account not only the environmental factors but also the community level socioeconomic factors. In Nepal, KA is confined to 12 low altitude tropical climate districts of the country and a number of studies have mentioned a host of socio-economic, cultural, environmental and governance factors as the root causes of the

Correspondence

Shiva Raj Adhikari

Centre for Health Economics, Faculty of Economics, Chulalongkorn

University, Bangkok, Thailand

E-mail: sssadhikari@yahoo.com 
disease $\mathrm{e}^{3,4,5,6,7,8}$. Community-level poverty is both a cause and a consequence of poverty and the vicious cycle of poverty and KA makes it one of the most intractable problem for poor communities of the country ${ }^{5,9}$.

Although the possible determinants of KA in endemic countries have been widely reported, most studies appear to base the conclusions by using either qualitative approaches or subjective speculations. Nevertheless, the literature consistently supports the conclusion that poverty is an important cause of KA in endemic areas ${ }^{4,5,10}$. This information alone is not helpful to policy makers who would like to find out the possible consequences of poverty reduction on KA incidence as well as what policy options one can use to break the vicious cycle of poverty and infectious diseases ${ }^{9}$. Only a few studies ${ }^{11,12}$ have attempted to analyze the risk factors of KA by utilizing household level data but none indicates in quantitative terms the potential effects of various factors on the incidence of KA.

Since KA is usually fatal within a short period of time, KA cases are often assumed as incident cases. In this study, KA incidence has been expressed in terms of cases per ten thousand population. Since KA adversely affects the economic situation of households, it makes the relatively poor households even poorer ${ }^{5,13}$. In Nepal, $\mathrm{KA}$ is primarily confined to twelve districts of Terai belt bordering the State of Bihar, India. In fact, KA is a common public health problem of Bangladesh, India and Nepal and regional collaborative efforts should be undertaken to control the disease $\mathrm{e}^{3,14,15}$. The Governments from these three KA endemic countries have recently made their commitments to eliminate KA from the Indian sub-continent ${ }^{15}$. The target annual incidence rate has been set at less than one case per ten thousand population by $2015^{3,15}$. In Nepal, reported incidence rates have varied from about four to five cases per ten thousand since 2000 and therefore, considerable improvements will be required to achieve the target rate by 2015. Fig. 1 shows the incidence rate of KA in Nepal over the years 1980 to 2006. Nepal's experience clearly indicates that the existence of an effective disease control program is not enough for reducing the incidence of KA. In fact, the incidence of KA in Nepal has been increasing over the last one decade despite the presence of highly visible KA control and treatment program.

This paper contributes to the literature by quantifying the effects of socioeconomic factors on the incidence of KA at the community level. Multivariate regression model has been used to identify the factors affecting KA incidence by utilizing community level variables collected from various sources.
This paper is organized as follows: the second section below presents the KA incidence scenario in Nepal. In the third section, we discuss the methods and materials used and the empirical strategy employed. The empirical results are presented in the fourth section and the fifth section discusses the results and policy implications. Concluding observations are presented in the last section.

\section{Materials and methods}

Research design: The study used descriptive and causal comparative econometric design. Cross sectional data were collected from primary and secondary sources. The study has focused on two issues: estimating the determinants of burden of disease in the community and measuring in quantitative terms the potential effects of poverty alleviation programmes on incidence of KA. Methodological triangulation was employed in the data collection, analysis and interpretation in order to improve quality of research. Information on community level characteristics was obtained from different sources for $204 \mathrm{KA}$ endemic communities (ilaka) for 12 districts. The community is the unit of analysis in this study.

Sources of data: This research is based on the analysis of cross sectional small area data. The data needed for the study were collected from different sources, both primary and secondary. Secondary sources are the documents and reports published by the Central Bureau of statistics (CBS), Ministry of Health and Population (MOHP), External Development Partners (EDPs) and other published and unpublished literatures. Community level poverty data were available for small areas (ilaka level) in CBS report $2006{ }^{16}$. Ilaka is a group of villages that is defined by CBS. All KA endemic districts of Nepal are divided into 204 small areas. Therefore, we collected required data based on 204 small areas. Data on KA cases were obtained from records, files and reports of district public health offices and central offices. Data were triangulated from various sources to maintain reliable and accuracy of data, for example, if the communities were not identified from the district health offices, data were grouped and regrouped according to identified communities with the help of local people. Other data that were not available in the districts or in the community were collected from central offices, such as publications of CBS. Community level variables used in the analysis are: the number of KA cases in the area, population at risk, incidence, intensity and severity of poverty, population density, per capita government expenditure, coverage of clean drinking water supply, infrastructural characteristics etc. However, a number of important variables like access to health care services, caste, urbanization and other environment related data at the community level were not available. 
We, therefore, decided to use some proxy variables, such as percentage of disadvantaged population as a proxy for caste and contraceptive prevalence rate (CPR) as a proxy for healthcare access. Although CPR is not related to the disease, higher CPR indicates better access to health services. Only the KA incidence and poverty rates are available for the individual small areas (ilaka) and all other variables are district specific. All data were transferred into Statistics/Data Analysis Stata Corp. STATA 10.1 statistical packages for analysis.

Definition of variables: Most of the community related information was for 2003/04, although the community level KA incidence data were available for 2004 to 2006. To ensure consistency with other community level variables and minimize the possible missing cases, this study has used average KA cases for the year 2004 to 2006 . The community level poverty measures were also available at the small-area level and this study has used the published poverty incidences. Factors reflecting the preventive aspects of KA were measured by coverage of drinking water. Road density, measured as kilometers $(\mathrm{km})$ of road per 100 square $\mathrm{km}$ area, was used as a variable for infrastructural development. For infectious diseases like KA, population density should affect transmission probability positively. We have also included total governmental development expenditure in the district per person to indicate the possible effects of governmental inputs in overall development and quality of public services. For each of the districts, proportion of population disadvantaged was defined as the percent of minority caste/ ethnic population living in the area where literacy rate among them is no more than $30 \%$. CPR is defined as number of fertile couples using contraceptives per 100 married women of reproductive age. Table 1 lists all the variables used in the analysis.

Statistical methods: In this study, we have used regression model to identify the factors explaining the variability of KA incidence rates across small areas. We have used ordinary least square for the empirical estimation of the equation. In general form, the regression model can be written as:

$K A_{i}=F($ Poverty; dwater; road; pop; govtexp; edu; dispo; cpr).......(1)

Where, $K A i=\mathrm{KA}$ incidence rate in the ith community poverty $=$ poverty incidence, or intensity or severity at community level

$d w a t e r=$ percentage of safe drinking water road $=$ road density pop= population density govtexp $=$ governmentdevelopmentexpenditure

(in Nepali rupees) $e d u=$ literacy rate

dispop $=$ percent of population disadvantaged $c p r=$ Contraceptive prevalence rate (proxy for use services)

Results

Summary statistics: Average KA incidence for the years 2004, 2005 and 2006 was found to be about 2.43 per ten thousand population in the $12 \mathrm{KA}$ endemic districts of Nepal. Average poverty incidence in these communities was 27 percent. More than 90 percent people had access to drinking water. Less than 50 percent people were literate. Almost 30 percent population were categorized as disadvantaged and minority population. Descriptive statistics for other community level variables are presented in table 2 .

Among the variables listed, we expect that poverty and population density should have positive impact on KA incidence. By contrast preventive measures, road, education, government expenditure and drinking water should reduce the incidence of KA. We have used CPR as a proxy for health knowledge and willingness to utilize health services in general. Since it is not specific to KA, this may not turn out to be important in empirical estimation. The percent of population disadvantaged, defined as minority population group with low educational attainment, may capture some aspects of social exclusion and disparity. Table 3 reports the estimated coefficients of the regression model.

F statistic of the regression equation shows that the independent variables are jointly statistically significant at $1 \%$ level. Although the $\mathrm{R}^{2}$ value is not very low, it is lower than what is expected for cross-sectional geographic analysis. All independent variables are statistically significant in a two-tailed test at $1 \%$ or $5 \%$ or $10 \%$ significance levels. The results of the regression model suggest that poverty incidence rate, population density and CPR affect the KA incidence rates across the small areas positively. The direction of the coefficient of CPR in the model was not expected. This probably indicates that the measure is not a good proxy for access to healthcare services in the area.

For easy interpretation of the coefficients estimated, we have calculated the elasticity measures from the coefficients. The elasticity measures are independent of scale of measurement of the dependent and independent variables and can be interpreted or compared easily. The elasticity measures indicate that one percent increase in poverty incidence rate increase the KA rate by $1.6 \%$ while one percent increase in population density increases the KA rate by 5.74 percent. Access to quality drinking water, higher road density, higher literacy or increased governmental expenditures in development activities all reduce the incidence of KA. Increased governmental development expenditure per capita or 
higher road density per area can also reduce the KA incidence rates but these variables will have relatively small impact on KA.

We estimated impact of incidence, intensity and severity of poverty on KA incidence. We found similar magnitude and direction of these impacts and have reached conclusion on that poverty incidence only can efficiently measure the link between poverty and the disease.

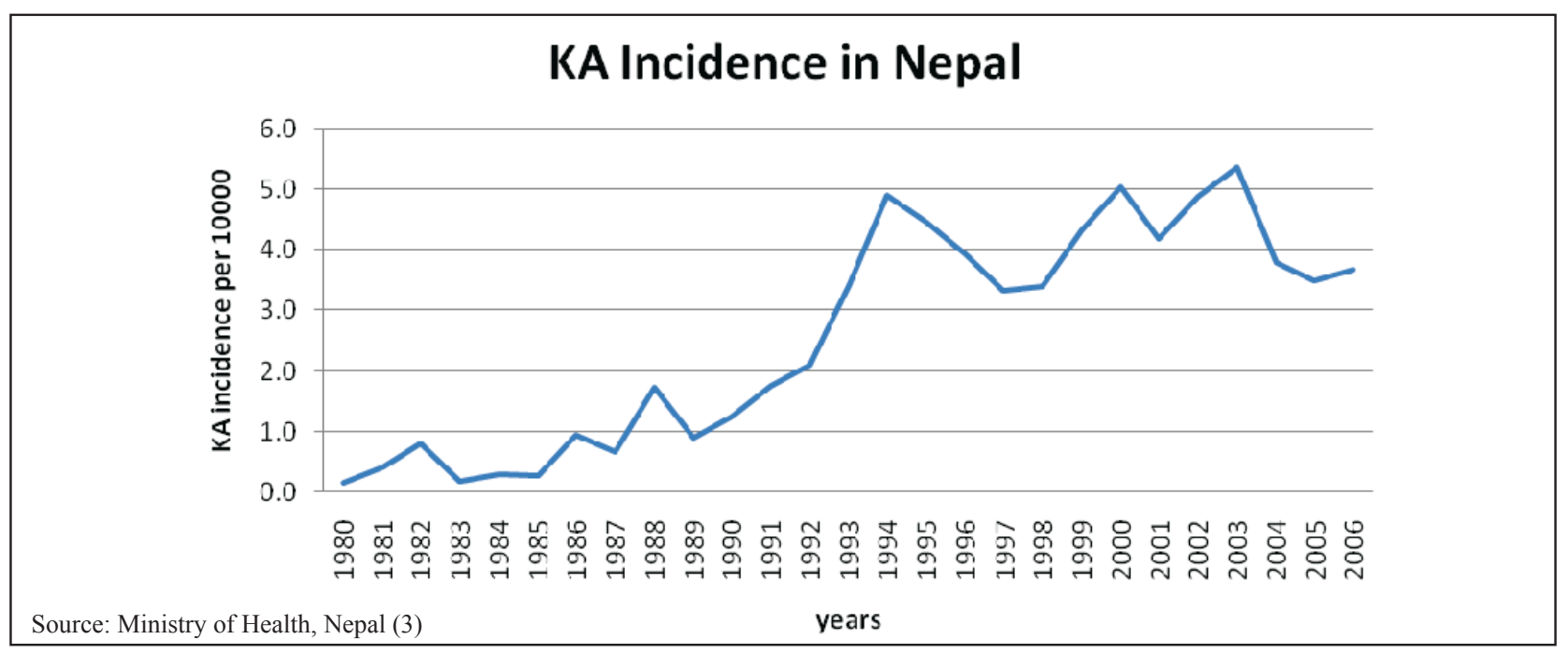

Fig 1: Incidence Rate of Kala Azar in Nepal, 1980-2006.

Table 1: List of Relevant Variables for the analysis of Kala Azar in Nepal

\begin{tabular}{|l|l|l|c|}
\hline Characteristics & Category & Description & Sources \\
\hline KA incidence & Continuous & Estimated average KA incidence for 2004, 2005, and 2006 & 3 \\
\hline Poverty & Continuous & $\begin{array}{l}\text { Estimated incidence, intensity and severity of poverty at the small } \\
\text { community level }\end{array}$ & 16 \\
\hline Drinking water & Continuous & $\begin{array}{l}\text { Percentage of households with access to piped or tap and tube-well } \\
\text { water for drinking purposes }\end{array}$ & 17 \\
\hline Road & Continuous & $\begin{array}{l}\text { Road-density in km per 100 square kilometer square of area of the } \\
\text { district }\end{array}$ & 17 \\
\hline Population & Continuous & Population per square kilometer of area of the districts & 17 \\
\hline $\begin{array}{l}\text { Government } \\
\text { expenditure }\end{array}$ & Continuous & Governmental development expenditure per capita & 17 \\
\hline Education & Continuous & Overall literacy rate in percent & 17 \\
\hline $\begin{array}{l}\text { Disadvantaged } \\
\text { population }\end{array}$ & Continuous & $\begin{array}{l}\text { Percentage of disadvantage (minority caste and ethnic groups) } \\
\text { population with literacy rate below or equal to 30 }\end{array}$ & 17 \\
\hline $\begin{array}{l}\text { Contraceptive } \\
\text { prevalence rate }\end{array}$ & Continuous & $\begin{array}{l}\text { Number of fertile couples using contraceptives per } 100 \text { married } \\
\text { women of reproductive age }\end{array}$ & 17 \\
\hline
\end{tabular}


Table 2: Summary results

\begin{tabular}{|l|c|c|c|c|c|}
\hline Community Variables & Observations & Mean & Std. Dev. & Min. & Max. \\
\hline Average KA cases ( 04, 05, \&06) & 204 & 02.43 & 3.64 & 0.00 & 21.91 \\
\hline Poverty incidence & 204 & 26.94 & 10.29 & 6.5 & 67.7 \\
\hline Poverty intensity & 204 & 06.65 & 3.55 & 1.3 & 23.6 \\
\hline Poverty severity & 204 & 02.42 & 1.61 & 0.4 & 10.6 \\
\hline Drinking water & 204 & 91.02 & 6.80 & 69.71 & 97.10 \\
\hline Road density & 204 & 31.89 & 10.5 & 9.65 & 50.59 \\
\hline Population density & 204 & 455.55 & 95.41 & 139 & 569 \\
\hline Govt. Development Expend. & 204 & 673.78 & 497.62 & 307.00 & 2051.00 \\
\hline Contrace. Prevalence (CPR) & 204 & 38.90 & 10.77 & 25.14 & 60.05 \\
\hline Percent pop disadvantaged & 204 & 29.65 & 14.99 & 10.11 & 65.4 \\
\hline Literacy & 204 & 47.63 & 10.61 & 32.74 & 67.14 \\
\hline
\end{tabular}

Sources: Calculated from the data set assembled for the study.

Table 3: Estimated influences of community variables on KA incidence

\begin{tabular}{|c|c|c|c|c|}
\hline Variables & Coefficients & Std. Err. & Elasticity & Std. Err. \\
\hline Poverty incidence & $* 0.14$ & 0.0382 & $* 1.60$ & 0.4497 \\
\hline Drinking water & $*-0.25$ & 0.0742 & $*-9.44$ & 2.9196 \\
\hline Road density & $* * *-0.11$ & 0.0635 & $* *-1.48$ & 0.8441 \\
\hline Population density & $* 0.03$ & 0.0091 & $* 5.74$ & 1.7895 \\
\hline Govt. Devt. Exp. & $* * *-0.01$ & 0.0009 & $* * *-0.43$ & 0.2639 \\
\hline CPR & $* 0.26$ & 0.0868 & $* 4.22$ & 1.4447 \\
\hline$\%$ disadvantaged & $*_{-0.09}$ & 0.0279 & $*-4.42$ & 1.5953 \\
\hline Literacy & $*_{-0.23}$ & 0.0786 & $*-1.12$ & 0.3570 \\
\hline Constant & $* * 15.40$ & 6.9411 & \multicolumn{2}{|c|}{ Elasticities after regress } \\
\hline F( 8, 195) & $=$ & 6.14 & \multicolumn{2}{|c|}{ Fitted values (predict) } \\
\hline Prob $>$ F & $=$ & 0.0000 & \multicolumn{2}{|c|}{2.4326454} \\
\hline R-squared & $=$ & 0.2012 & & \\
\hline Adj R-squared & $=$ & 0.1685 & & \\
\hline Root MSE & $=$ & 3.3208 & & \\
\hline
\end{tabular}

Note: $*$ significant at $1 \%$ level, $* * 5 \%$ level and *** $10 \%$ level

Source: estimated.

\section{Discussion}

The important risk factors of KA ranges from environmental and geographic features to poverty, government expenditure, population density, infrastructure development, etc. In this analysis, we found that a number of community level variables are important in explaining the regional variation of KA in the endemic districts of Nepal. Poverty incidence in an area is associated with the KA incidence rate. One percent reduction in poverty incidence should reduce KA incidence by about $1.6 \%$, implying that poverty reduction will be a very effective mechanism of reducing $\mathrm{KA}$ in the area. If the poverty incidence can be reduced from the existing level of 27 percent to about 16 percent, the KA target rate can be achieved by 2015 .
In addition to poverty reduction, improvements in water supply, literacy, governmental expenditure can also help in reducing KA incidence rates in the area. Another intervention that can reduce KA rate significantly is the improvements in access to safe drinking water; increase in access to clean water by one percent is likely to reduce $\mathrm{KA}$ incidence rate by $9.4 \%$.

Generating, synthesizing and interpreting evidence on the social determinants of infectious disease is feasible and quantifying the underlying determinants of KA and their elasticity is possible but addressing the KA incidence remains difficult and challenging. One of the difficulties is that the links between the disease and the 
socio economic factors are multiple and complex and often the inter-correlations among the community level factors make it difficult to identify the proximate causes or factors ${ }^{2,5,9}$. The precise causal pathways from various socioeconomic factors to disease incidence are not fully understood and this gap in our knowledge has affected our ability to identify the most important determinants of KA. Untangling the relationship between burden of disease and socioeconomic status has proven to be a difficult process. For example, the association between poverty and infectious disease reflects causality running in both directions: poverty breeds disease, and disease keeps poor people poor. Unless longitudinal data are used, it is not possible to quantify the effects of the variables on KA incidence and the effect of KA incidence on the potential socioeconomic factors.

The multivariate analysis confirmed that burden of KA is disproportionately borne by vulnerable and marginalized groups. KA is most entrenched in the poorest communities. Poverty in the community is one of the primary determinants of KA. If the incidence of poverty declines by 10 percent, it will lead to reduction in KA incidence by $16 \%$ at the community level. This result contradicts the results reported by Bern et al, 2005 who found that income, land ownership and other assets were not important as determinants of KA in Bangladesh ${ }^{18}$. Some studies did find poverty and infectious disease links ${ }^{5,7,13,19,20}$. In the analysis of KA, poverty-disease incidence link is difficult to establish due to the interactions between these two variables $5,9,21,22$.

Finally, we should mention some of the limitations of the study methodology and data. The most important limitation is the lack of reliable data on KA disease incidence rates by community. This study has used information collected at the health facility level to generate geographic distribution of the disease. Although about $80 \%$ of KA cases show up in health facilities ${ }^{23}$, it is still a significant underestimation of community level incidence. Proportion of KA patients seeking care from health facilities may also be different for different communities, thus distorting the community level incidence rates. Another limitation of the study is that not all variables are available in Nepal for the small areas used as the unit of analysis here. For example, a number of variables are actually district specific and we have assigned district level average values to the small areas in the district.

\section{Conclusions}

At least three points are worth highlighting in the conclusions. First, little is known about the relative importance of characteristics of community in the determinants of incidence of KA. The multivariate analysis has confirmed that some of the community characteristics, for example, poverty, population density, contribute to increase incidence of KA; however, access to safe drinking water, infrastructure development, literacy contribute to reduce incidence of KA. Government expenditure pays roles in supply side efficiency in producing public services. Second, the association between poverty and KA reflects causality running in both directions: poverty multiplies KA incidence and KA pushes poor into marginal poor or further poverty. Third, the strategy for disease control or elimination should shift from traditional diseasecentered approaches to a holistic approach that can break the links between poverty and KA.

Acknowledgement: UNICEF/UNDP/World Bank/ WHO Special Program for Research and Training in Tropical Diseases (TDR) has provided financial support for $\mathrm{PhD}$ study of Shiva Raj Adhikari. We would like to thank Pirom Kamol-Ratanakul, Pongsa Pornchaiwiseskul, Sumalee Pitayanon, Wattana Suwansang Janjaroen, Bishnu Prasad Sharma and anonymous reviewers for providing valuable comments on an earlier draft, with the errors being the sole responsibility of the authors.

\section{References}

1. Desjeux P,The Increase in Risk Factors for Leishmaniasis Worldwide, Transactions of the Royal Society of Tropical Medicine \& Hygiene, 2001.95: 239-243.

2. Remme JHF, Feenstra P, Lever PR, Médici A, Morel C, Noma M, Ramaiah KD, et al “Tropical Diseases Targeted for Elimination: Chagas Disease, Lymphatic Filariasis, Onchocerciasis, and Leprosy" in chapter 22 :Disease Control Priorities in Developing Countries. Second edition, (2006) Oxford University Press and The World Bank

3. Ministry of Health and Population Department of health services, Epidemiology and disease control division The international Assessment of Malaria and Kala Azar Control Activities 2004, 2005 and 20062007 Government of Nepal Ministry of Health and Population

4. Wijeyaratne PM., Jones-Arsenault LK., Murphy CJ, Endemic disease and development: the leishmaniases Acta Tropica, 1994 56: 349-364

5. Alvar J, Yactayo S, Bern C, Leishmaniasis and poverty. TRENDS in Parasitology 2006. 22: 552-7.

6. Desjeux P, Leishmaniasis: current situation and new perspectives Comparative Immunology, Microbiology \& Infectious Diseases 2004. 27 : 305-318 
7. Pond,M. A., Interrelationship of Poverty and Disease Public Health Reports (1896-1970), $196176: 967-974$

8. Sharma BP, Maskay NM, Adhikari SR, Socioeconomic determinants of Kala-azar in Nepal Journal of Nepal Health Research Council 2004 2 (1) pp 35-42

9. Marmot M, Social determinants of health inequalities Poverty, social determinants and health research Global Forum Update on Research for Health 2009 Volume 2 pp 33-39

10. Rosenfield PL, Widstrand CG, And Ruderman AP, Social And Economic Research In The Undp/World Bank/Who Special Programme For Research And Training In Tropical Diseases, Social Science And Medicine, 1981 Vol 15a pp 529-538

11. Ranjan A, Sur D, Singh VP, Siddique NA, Manna B, Lal CS, et al. Risk Factors for Indian Kala-Azar Am. J. Trop. Med. Hyg., 73(1), 2005, pp. $74-78$

12. Bern $\mathrm{C}$, and Chowdhury $\mathrm{R}$, The epidemiology of visceral Leishmaniasis in Bangladesh: prospects for improved control Indian J Med Res 123, March 2006, pp 275-288

13. Adhikari SR., Maskay NM, and Sharma BP, Paying for Hospital-Based Care of Kala-Azar in Nepal: Assessing Catastrophe, Impoverishment and Economic Consequences, Health Policy and Planning, 2009 Mar; 24 (2):129-39

14. Kishore K, Kumar V, Kesari S, Dinesh DS, Kumar AJ, Das P, and Bhattacharya SK, Vector control in leishmaniasis Indian J Med Res 123, March 2006, pp 467-472

15. WHO/SEARO, Regional Strategic Framework for Elimination of Kala-azar from the SouthEast Asia Region (2005-2015): 2005 WHO Project No.: IND CRD 714 World Health Organizations/ South East Asia Regional Office, New Delhi

16. Central Bureau of Statistics (CBS), UNDP, and World Bank, Small area estimation of poverty, Caloric Intake and Malnutrition in Nepal Central Bureau of Statistics, Nepal, United Nations World Food Programme, Nepal and the World Bank(2006)
17. Central Bureau of Statistics (CBS), ICIMOD, Districts of Nepal: Indicators of Development, Central Bureau of Statistics Nepal and International Centre for Integrated Mountain Development ICIMOD/MENRIS) with the support of SNV-Nepal December 2003

18. Bern C, Hightower AW, Chowdhury R, Ali M, Amann J, Wagatsuma Y, Haque R, Kurkjian K, Vaz LE, Begum M, Akter T, Cetre-Sossah CB, Ahluwalia IB., Dotson E, Secor WE, Breiman RF, and Maguire JH Risk Factors for Kala-Azar in Bangladesh Emerging Infectious Diseases 2005 Vol. 11, No. 5: 655- 662

19. Conteh L, Engels M, Molyneux DH, Socioeconomic aspects of neglected tropical diseases Lancet 2010; 375: 239-47

20. Holveck JC, Ehrenberg JP, Ault SK, Rojas R, Vasquez J, Cerqueira MT, Ippolito-Shepherd J, et al Prevention, control, and elimination of neglected diseases in the Americas: Pathways to integrated, inter-programmatic, inter-sectoral action for health and development BMC Public Health 2007,7:6 pp 1-21

21. Baker MC, Mathieu E, Fleming F, Deming M, King JD, Garba A, Koroma JB, Bockarie M, Kabore A, Sankara DP, Molyneux DH, Mapping, monitoring, and surveillance of neglected tropical diseases: towards a policy framework Lancet 2010; 375: 231-38

22. Ahluwalia IB, Bern C, Costa C, Akter T, Chowdhury R,.Ali M, Alam D, Kenah E, Amann J, Meghla Islam M, Wagatsuma Y, Haque R, Breiman RF, and Maguire JH, Visceral leishmaniasis: consequences of a neglected disease in a Bangladeshi community American Journal of Tropical Medicine and Hygiene 2003 69: 624-8

23. Institute of Medicine, and BP Koirala Institute of Health Sciences Implementation Research for an Improved Strategy of Diagnosis, Treatment and Follow-up of Kala-azar Patients (Phase II) Submitted to: UNDP/World Bank/WHO Special Programme for Research and Training in Tropical Diseases (TDR) (2008) unpublished Institute of Medicine, Tribhuvan University, Kathmandu and BP Koirala Institute of Health Sciences, Dharan, Nepal 